\title{
Vaginal Estrogen Therapy for Patients with Breast Cancer
}

\section{Vaginale Östrogentherapie bei Patientinnen mit Mammakarzinom}

Authors

Affiliation
M. Moegele, S. Buchholz, S. Seitz, C. Lattrich, O. Ortmann

University Medical Center Regensburg, Department of Gynecology and Obstetrics, Regensburg

\section{Key words \\ - breast cancer \\ vaginal atrophy \\ - hormone therapy \\ - quality of life \\ Schlüsselwörter \\ - Mammakarzinom \\ - Vaginalatrophie \\ - Hormontherapie \\ - Lebensqualität}

Deutschsprachige Zusatzinformationen online abrufbar unter: www.thieme-connect.de/ ejournals/toc/gebfra

\section{Abstract \\ $\nabla$}

On account of the good prognosis for patients with breast cancer, improving or maintaining the quality of life in the aftercare period is becoming more and more important. In particular, the increasing usage of aromatase inhibitors in the past few years has led to an increased incidence of vaginal atrophy with symptoms such as vaginal dryness, petechial bleeding, dyspareunia and recurrent cystitis. And just these symptoms have a detrimental impact on the quality of life of breast cancer patients. Application of a topical estrogen therapy represents the most effective means to treat vaginal atrophy. The use of a systemic or, respectively, topical hormone therapy is, however, contraindicated for breast cancer patients. Further clinical trials are needed in order to assess the safety of vaginal estrogen therapy.

\section{$\nabla$}

The advances in the diagnosis of and therapy for breast cancer in the past few years have led to a declining mortality of breast cancer [1]. On account of the good prognosis for the disease, many patients suffer from long-term side effects that may be caused by operations, radiotherapy, chemotherapy, or endocrine therapy. Thus, improvement or, respectively, maintenance of quality of life is becoming increasingly important in the aftercare of breast cancer patients. The increasing wish for treatment of climacteric complaints is shown in $\bullet$ Fig. 1.

About $75 \%$ of climacteric patients experience menopausal complaints such as hot flushes, sleeping disorders, decline in libido and vaginal atrophy. The average age of onset of breast cancer is about 62 years, thus most patients are in the

\section{Zusammenfassung \\ $\nabla$}

Aufgrund der guten Prognose von Mammakarzinompatientinnen nimmt die Verbesserung bzw. Erhaltung der Lebensqualität in der Nachsorge einen zunehmenden Stellenwert ein. Gerade der vermehrte Einsatz von Aromatasehemmern hat in den vergangenen Jahren zu einer Zunahme der vaginalen Atrophie mit Symptomen wie Scheidentrockenheit, petechialen Blutungen, Dyspareunie und rezidivierenden Zystitiden geführt. Gerade diese Symptome beeinflussen in gravierender Weise die Lebensqualität von Mammakarzinompatientinnen. Die Anwendung einer lokalen Östrogentherapie stellt die effektivste Behandlungsform der Vaginalatrophie dar. Die Anwendung einer systemischen bzw. einer lokalen Hormontherapie bei Brustkrebspatientinnen ist jedoch kontraindiziert. Zur Beurteilung der Sicherheit einer vaginalen ET sind weitere klinische Studien erforderlich.

postmenopause at the first diagnosis of breast cancer. The majority of these patients suffer from hormone receptor-positive breast cancer and thus receive an adjuvant endocrine therapy with tamoxifen or aromatase inhibitors (AI). In many of the cases these therapeutic options lead to an increasing rate of estrogen deficiency symptoms [2]. And just the increasing usage of AIs in postmenopausal breast cancer patients leads to an increase of vaginal atrophy with symptoms such as vaginal dryness, petechial bleeding, dyspareunia and recurrent cystitis [3]. In a retrospective evaluation of the Swedish cancer register, a significant number of severe vaginal atrophies were found among users of AIs as compared with patients under tamoxifen therapy (33.3 vs. 5.95\%) [4]. These results can also be reconstructed in older study evaluations $[5,6]$. After an appropriate check for contraindications and oncological 


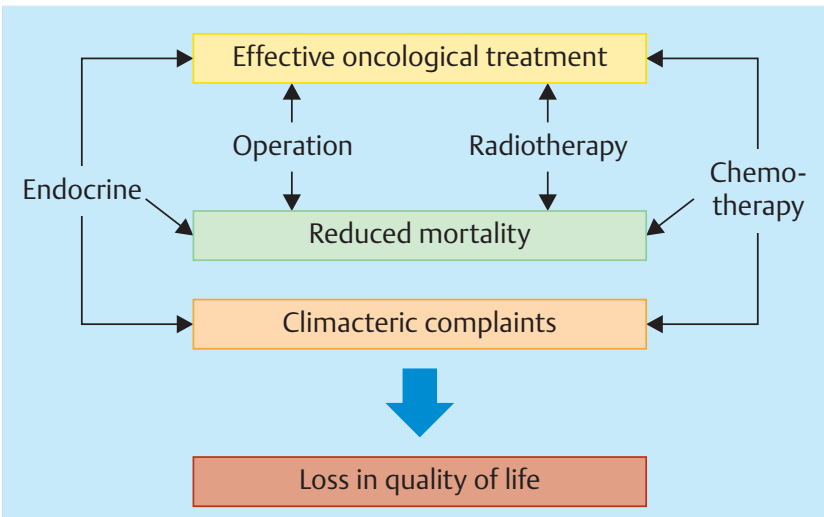

Fig. 1 Increasing wish for treatment of climacteric complaints.

safety, a switch from endocrine therapy to tamoxifen may be discussed with the respective patients [7].

The symptoms of vaginal atrophy have a severe detrimental effect on the quality of life of breast cancer patients and it is estimated that up to $20 \%$ of all patients do actually terminate or consider terminating their adjuvant endocrine therapy for this reason [8]. The most effective treatment for vaginal atrophy comprises the use of a topically applied estrogen therapy [9]. However, the use of not only systemic but also topical hormone therapy $(\mathrm{HT})$ is contraindicated for breast cancer patients $[10,11]$.

In the following paragraphs the current data situation on the use of hormone-containing, topically applied formulations by breast cancer patients is presented and possible alternatives are discussed.

\section{Diagnosis of Vaginal Atrophy}

When serum estradiol level decreases below $73 \mathrm{pmol} / \mathrm{l}$ postmenopausal patients can develop a clinically relevant vaginal atrophy. An exact knowledge of the symptoms of vaginal atrophy is necessary in order to make a rapid and targeted diagnosis. The diagnosis of vaginal atrophy is generally made in the course of a gynaecological examination. Here, attention should be paid first of all to dry vaginal mucous membranes and possible petechial haemorrhages or, respectively, bleeding on contact. Patients often report on accompanying dyspareunia, itching and burning sensations. Furthermore, breakage of collagenous reinforcement fibres in the vaginal epithelium can lead to a loss of vaginal membranous folds, the so-called rugae of the vagina.
Table 1 Symptoms of a vaginal atrophy (adapted after [47]).

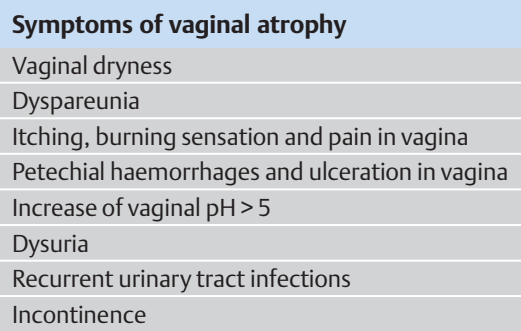

An increase of the vaginal $\mathrm{pH}$ value to a basic value $>5$ can be an indication for a vaginal infection caused by reduced colonisation of the vagina by lactobacilli. A summary of the clinical symptoms of vaginal atrophy is given in $\bullet$ Table 1.

Due to the close embryological relationship of the female urinary bladder and urethra with the vaginal system, they all have a high density of estrogen receptors. This can lead to recurrent cystitis and prolapse complaints due to a postmenopausal or therapy-induced decline of the serum estradiol level.

As supplement to clinical diagnostics, the vaginal maturation index (VMI) has proved its value as a standard score in the cytological diagnosis of vaginal atrophy. The VMI describes the relative ratio of parabasal and intermediate cells to superficial cells in the vaginal epithelium. A proportion of $>15 \%$ superficial cells is defined as a physiological finding. In postmenopausal patients values of less than $5 \%$ can be found.

Many patients are not aware of the relationship between postmenopausal estrogen deficiency and vaginal atrophy. Only few patients seek consultations with their gynaecologist about treatment options. Upon diagnosis of vaginal atrophy in the course of gynaecological examinations, the patients should be informed about the symptoms and their treatment options by their gynaecologist. The initiation of a local HT depends on the degree of distress of the individual patient.

An algorithm for the clinical diagnosis of vaginal atrophy is presented in $\bullet$ Table 2 .

\section{Breast Cancer Risk due to HT}

$\nabla$

The usage of HT increases the risk of developing breast cancer. The increased risk becomes apparent after duration of use of 5 years or more. In the past few years the relationship between HT and breast cancer has been mostly investigated in observational trials. These have come to differing assessments of the risks of

Table 2 Algorithm for clinical diagnosis of vaginal atrophy (adapted after [47]).

\begin{tabular}{|c|c|c|c|}
\hline & \multicolumn{3}{|c|}{ Vaginal atrophy } \\
\hline & mild & moderate & severe \\
\hline Vaginal pH & $>4.5-5$ & $>5$ & $>6.1$ \\
\hline Pallor & light pink & very pale & white or red \\
\hline Redness & barely & subtle & strong \\
\hline Ulceration & no & no & yes \\
\hline Moistness & reduced & minimal & absent \\
\hline Petechial haemorrhages & present & bleeding on scratching & bleeding on contact \\
\hline Maturation Index* & $<5 \%$ & & \\
\hline
\end{tabular}

* Describes the ratio between parabasal, intermediate and superficial cells 
a purely estrogen therapy (ET) or, respectively, of a combination therapy with estrogens and progesterone (EPT). These studies showed that EPT increases the risk more than ET does. Furthermore, the relatively low risk increase due to ET is apparent only after a markedly longer period of use ( $>7-10$ years).

In this context, special mention must be made of the results of the Women's Health Initiative (WHI) study. Altogether 16608 women aged from 50 to 79 years participated in the trial. After 5.2 years the study was prematurely terminated since the combined HT had increased the risk of coronary heart diseases, thromboembolic events and breast cancer. For EPT use of 5 or more years duration, the absolute risk in the WHI trial amounted to 8 additional breast cancers per 10000 women/year [12]. Subsequent investigations of the WHI post intervention phase additionally revealed an increased mortality due to breast cancer. In the follow-up observation group of 12788 patients there were 25 deaths due to breast cancer per year in comparison to 12 deaths in the control group treated with placebo [13]. More recent evaluations of the WHI data show that use of EPT for less than 5 years can also lead to an increase of the breast cancer risk [14]. The breast cancer risk under and after ET with an average duration of use of 5.9 years is lower [15]. This effect is significant and differs from data collected in observational trials. Several further meta-analyses, cohort studies and randomised trials have demonstrated an increased risk of breast cancer after EPT [1619].

\section{HT after Breast Cancer}

The relative risk (RR) for a breast cancer recurrence due to the use of HT was examined in a systematic review by Col et al. [20]. Altogether 11 trials with 669 breast cancer patients who had received HT were analysed. Merely 4 of the 11 trials included a control group and in these no significantly increased recurrence rate could be detected. The yearly recurrence rate amounted to $4.2 \%$ after an observation period of 30 months. A recurrence of breast cancer was diagnosed in 17 patients (8\%) under HT in comparison to 66 patients (11\%) without HT (RR 0.64). Taken together, in a total of 11 analysed studies (7 uncontrolled trials) on 669 breast cancer patients with HT there was no significant increase in the recurrence of breast cancer with an RR of 0.82 [20]. The case numbers in these studies were, however, too small to enable an unambiguous conclusion to be drawn about the safety of HT in this patient collective.

The effects of systemic HT after breast cancer disease were examined in 2 independent, prospective randomised trials.

In the HABITS trial (Hormonal Replacement Therapy after Breast Cancer - Is it Safe?) 434 patients aged from 40 to 75 years were enrolled. The study had to be terminated in 2003 due to an increased risk of breast cancer recurrence with a hazard ratio (HR) of 3.3 (95\% confidence interval [CI]: 1.5-7.4) [21]. Altogether in 26 of 219 patients in the HT group and in 8 of 215 patients in the control group there was a recurrence of the known breast cancer. In contrast to this, in the Stockholm study no significantly increased recurrence risk among 378 postmenopausal breast cancer patients could be detected (HR: 0.82; 95\% CI: 0.35-19) [22]. Despite the higher proportion of lymph node-positive breast cancer patients in the HABITS trial, HT is contraindicated for patients after breast cancer.

On the other hand, the use of HT in patients with hormone receptor-negative breast cancer seems to be quite safe. In an un- planned subgroup analysis of the HABITS trial no increase in the recurrence rate could be detected [21]. Also in the WHI trial no increase in the recurrence rate for hormone receptor-negative breast cancers could be detected [12]. Even so, patients with hormone receptor-negative breast cancers should be treated analogously to those with hormone receptor-positive breast cancers on account of the inadequate data situation for an evaluation of the oncological safety [10].

Up to publication of the LIBERATE trial (Livial intervention following breast cancer: efficacy, recurrence and tolerability endpoints), tibolone, a synthetically produced steroid possessing estrogen, gestagen and androgen activities, was considered to be a potential low-risk therapeutic option for vasomotoric complaints in relation to HT. Although in the LIBERATE trial it could be shown that the use of tibolone $(2.5 \mathrm{mg})$ led to a significant improvement in vasomotoric complaints and bone density, 237 of 1556 patients on the other hand suffered from a recurrence of the previously known breast cancer, in comparison to 165 cases of recurrence among 1542 patients in the placebo group (HR 1.40; 95\% CI: 1.14-1.70) [23]. Thus, as a consequence of the consumption of tibolone the recurrence rate was increased by $40 \%$ and the incidence of metastases by $38 \%$. These data correspond with the results of subgroup analyses of the One Million Women Study and the HABITS trial in which similar data were gathered. The use of tibolone thus cannot be recommended for patients with breast cancer.

\section{Topical Oestrogen Therapy for Vaginal Atrophy $\nabla$}

Topical ET is a widespread and common routine treatment option for patients with vaginal atrophy.

Several meta-analyses have shown that, independently of its application form, topical ET can improve the signs of vaginal atrophy and its symptoms $[24,25]$. The use of topical ET, however, also makes possible the administration of lower estrogen dosages in comparison to systemic HT. It has been shown that a low-dose topical ET has the same efficacy as a systemic administration [25]. Thus, in cases with a sole indication for the treatment of vaginal atrophy, a topical vaginal ET should be preferred to a systemic therapy. This is also reflected in the current recommendations of the German S3 guidelines as well as in a position paper of the North American Menopause Society [10,25, 26].

Estradiol-, estriol- and estrone-containing formulations are available in Germany for topical ET. With regard to systemic estradiol absorption, upon application of a vaginal tablet with $25 \mu \mathrm{g}$ estradiol a merely minor systemic absorption at a still low serum estradiol level of $<14 \mathrm{pg} / \mathrm{mL}$ could be detected [27]. On comparison of an estradiol liberating vaginal ring with estradiol-containing vaginal tablets also only a minimal increase of the serum estradiol level could be recorded. On comparison of the two forms of administration no significant differences can be found. In addition, it has been shown that no endometrial proliferation is to be expected on use of topical ET [28]. An additional administration of gestagens cannot be recommended on the basis of the currently available data.

Estriol is a short-working estrogen with low potency that is irreversibly transformed into estradiol or estrone. The safety of estriol with regard to endometrial hyperplasia as well as its therapeutic efficacy for vaginal atrophy is well known [29,30]. In a prospective monocentric trial with 19 postmenopausal patients suffering from vaginal atrophy, the bioavailability of low-dose es- 
Table 3 Formulations for topical HT in Germany (source: Rote Liste ${ }^{\circledR}$, data as of $07 / 13$ ).

\begin{tabular}{|c|c|c|}
\hline $\begin{array}{l}\text { Oestriol } \\
\text { preparations }\end{array}$ & Dosage & $\begin{array}{l}\text { Vaginal applica- } \\
\text { tion form }\end{array}$ \\
\hline Cordes $^{\circledR}$ Estriol & $0.5 \mathrm{mg}$ & cream \\
\hline $\begin{array}{l}\text { Estriol-Ovulum Fem } \\
\text { Jenapharm }{ }^{\circledR}\end{array}$ & $0,5 \mathrm{mg}$ & suppositories \\
\hline Gynoflor ${ }^{\circledR}$ & $\begin{array}{l}0.03 \mathrm{mg}+50 \mathrm{mg} \\
\text { Lactobacillus acidophilus }\end{array}$ & tablets \\
\hline Oekolp ${ }^{\circledR}$ & $1 \mathrm{mg}$ & cream \\
\hline Oekolp ${ }^{\circledR}$ Ovula forte & $0.5 \mathrm{mg}$ & pessaries \\
\hline Oekolp ${ }^{\circledR}$ forte & $0,5 \mathrm{mg}$ & suppositories \\
\hline Oekolp ${ }^{\circledR}$ forte Kombi & $0,5 \mathrm{mg} / 1 \mathrm{mg}$ & $\begin{array}{l}\text { suppositories/ } \\
\text { cream }\end{array}$ \\
\hline Oestro-Gynaedron ${ }^{\circledR} \mathrm{M}$ & $\begin{array}{l}50 \mathrm{mg} / 100 \mathrm{mg} \text { dosing } \\
\text { by means of an applicator }\end{array}$ & cream \\
\hline Ortho-Gynest ${ }^{\circledR}$ & $0.5 \mathrm{mg}$ & suppositories \\
\hline Ovestin $^{\circledR}$ & $0.5 \mathrm{mg}$ & pessaries \\
\hline Ovestin $^{\circledR}$ & $1 \mathrm{mg}$ & cream \\
\hline Xapro $^{\circledR}$ & $1 \mathrm{mg}$ & cream \\
\hline Estring $^{\circledR}$ & $2 \mathrm{mg}(7.5 \mu \mathrm{g} / 24 \mathrm{~h})$ & ring \\
\hline Linoladio $^{\circledR} \mathrm{HN}$ & $\begin{array}{l}5 \mathrm{mg} / 100 \mathrm{~g}+0.4 \mathrm{~g} \\
\text { prednisolone }\end{array}$ & cream \\
\hline Linoladiol ${ }^{\circledR} \mathrm{N}$ & $10 \mathrm{mg} / 100 \mathrm{~g}$ & cream \\
\hline Vagifem $^{\circledR}$ & $25 \mu \mathrm{g}$ & tablets \\
\hline
\end{tabular}

triol $(0.03 \mathrm{mg})$ was recently examined. The patients received a once daily vaginal application of the trial medication for 21 days. Blood samples taken on days 1, 2, 6, 11, 16 and 22 were able to show an increase in the serum estriol concentration up to $42.1 \mathrm{pg} / \mathrm{mL}$ only during the first hour after application. Already after 12 hours the estriol concentration in all patients had fallen under the detection level of $5 \mathrm{pg} / \mathrm{mL}$ [31].

The efficacy of a fractionated estriol administration was already demonstrated in 48 postmenopausal patients in 2005. Through the fractionated application of an estriol-containing vaginal cream there was a rapid and significant improvement of the atrophic vaginitis with a reduction of the $\mathrm{pH}$ value and an increase of the VMI. The fractionated administration consisted in the 1 st week of 2 applications at intervals of 28 hours. In the weeks 2-4 the application interval amounted to 3 or, respectively, 4 days (application 2 times per week) [32]. In the daily routine the use of topical estriol in the form of a once daily application for the first 3-4 treatment weeks followed by a maintenance therapy of 2-3 applications per week has become established.

A summary of the formulations for topical HT currently available in Germany is given in $\bigcirc$ Table 3.

\section{Quality of Life \\ $\nabla$}

Due to the markedly better therapeutic options and a decreased mortality of breast cancer, an exact sexual case history is becoming more and more important in the aftercare period in order to detect therapy-related symptoms of vaginal atrophy and the thus accompanying decrease in quality of life. It is estimated that about $25 \%$ of the afflicted patients do not inform their responsible physician about the symptoms of urogenital atrophy. In addition, about $70 \%$ of the afflicted patients report that they had not been questioned about the symptoms of vaginal atrophy such as pruritus, burning sensation and dyspareunia [33]. Estrogens play a decisive role in modulating the haemodynamic processes of the sexual reaction. An estrogen deficit leads to, beside a reduction in size of the labia majora and minora, a decline in the clitoral tumescence and inadequate vaginal lubrication. In up to $20 \%$ of the afflicted women this leads to a deterioration of clitoral sensitivity and in up to $50 \%$ of them to dyspareunia [34]. Sexually active, postmenopausal breast cancer patients thus often complain about a severe impairment of their quality of life and their partnership relations.

\section{Vaginal ET after Breast Cancer}

Because of the possible systemic absorption and an eventually increased probability of recurrences the use of topical HT in breast cancer patients has been a subject of controversial discussion for some years.

The increased use of Als in endocrine therapy for breast cancer has led to a markedly increased rate of vaginal atrophy and decline in quality of life. In contrast to endocrine therapy with tamoxifen, the production of estriol is inhibited by the use of AIs. In the serum of these patients you can find estriol levels that have dropped to as little as $3 \mathrm{pmol} / \mathrm{L}$.

The use of topical HT in breast cancer patients has been investigated in only a few clinical trials.

In a small, prospective randomised study of 6 postmenopausal breast cancer patients under endocrine therapy with AL, Kendall et al. found a significant increase in the serum estradiol level from $\leq 5 \mathrm{pmol} / \mathrm{L}$ to $72 \mathrm{pmol} / \mathrm{L}$ upon use of low-dosed estradiolcontaining vaginal tablets $(25 \mu \mathrm{g})$ for 2 weeks [35]. However, after use for 4 weeks the serum estradiol levels in most of the thus treated patients dropped again to levels of $<35 \mathrm{pmol} / \mathrm{L}$. This result was confirmed by Wills et al. in a recently published study with a similar design. In this study 24 breast cancer patients with symptomatic vaginal atrophy under AI or, respectively, tamoxifen therapy received a topical HT with estradiol-containing vaginal tables $(25 \mu \mathrm{g})$ or, respectively, an estradiol-containing vaginal ring. Significant increases in the serum estradiol levels were observed in both groups [36]. These trial results clearly illustrate that a systemic absorption by the still highly vulnerable vaginal mucous membranes is possible just in the first weeks of use of topical HT. The thus resulting increase in the serum estrogen levels can lead to an increased risk of recurrence. In contrast, Dew et al. in a retrospective cohort study on the use of low-dose estradiol-containing vaginal tablets or an estriol cream with an average follow-up of 5.5 years did not find an increased risk of recurrence. In the study group comprising a collective of 1472 breast cancer patients, 69 (4.7\%) were mainly afflicted with a clinically symptomatic vaginal atrophy. In these patients vaginal ET in the form of an estriol cream $(0.5 \mathrm{mg})$ or estradiol vaginal tablets $(25 \mu \mathrm{g})$ were used. In the group of patients using vaginal ET a significant difference in the risk of recurrence compared with the control group could not be demonstrated [37].

With estriol a hormone-containing, short-acting topical therapy for vaginal atrophy is available which cannot be metabolised into more potent estrogens such as estradiol or estrone. The rapid alleviation of complaints due to estrogen deficiency by use of topical estriol therapy is well known [38]. Just recently it was shown in 436 patients that the same efficacy and safety could be achieved with very low-dose estriol formulations $(0.03 \mathrm{mg}$ ) [39]. In a prospective, randomised study of 10 postmenopausal breast cancer patients under endocrine therapy with AI it was found that the daily use of $0.5 \mathrm{mg}$ estriol for 2 weeks did not result in 
elevated serum levels of estriol or estradiol [40]. The efficacy of a lower dosed estriol cream $(0.25 \mathrm{mg})$ in comparison to estradiolcontaining vaginal tablets and non-hormonal lubricants was examined in a small study with 18 breast cancer patients. An equally significant improvement of the clinical symptoms was achieved with the low-dose estriol therapy in comparison to estradiol therapy. The use of a non-hormonal preparation led merely to a short-term improvement of the symptoms. However, serum estrogen levels were not determined [41].

In some earlier studies on postmenopausal patients, however, increases of the serum estriol concentrations to values between 100 and $150 \mathrm{pg} / \mathrm{mL}$ were observed within 2 hours after use of $0.5 \mathrm{mg}$ of estriol. An elevation of the serum estradiol level could not be detected [42]. We recently presented the data from a bicentric phase I study on the efficacy and safety of an ultralow vaginal estriol administration $(0.03 \mathrm{mg})$ in breast cancer patients with symptomatic vaginal atrophy under AI therapy. In all, 16 breast cancer patients were treated daily for 28 days with topical applications of estriol. This was followed by a maintenance therapy with 3 tablets per week for further 8 weeks. After the first application of estriol no elevations of the estrone or estradiol serum levels were detected. The serum estriol levels in 15 patients underwent a short-term elevation to a maximum value of $168 \mathrm{pg} / \mathrm{mL}$. At the latest after 6 hours elevated estriol levels were no longer detectable in any of the patients. Over a period of 12 weeks 15 of the patients did not exhibit any changes of their serum estriol levels. In one of the patients after 4 weeks an increase to $14.4 \mathrm{pg} / \mathrm{mL}$ was measured. The estrone and estradiol values were not elevated at any time. The detailed results of this study will be published in the near future [43].

Thus, large, prospective randomised studies for a final concluding assessment of the safety vaginal ET in breast cancer patients is still lacking. With the currently available data not only the use of a systemic but also that of a topical HT in breast cancer patients is contraindicated. Even so, on the basis of the above-mentioned results from studies with ultralow dosed estriol, it can be assumed that this therapy is safe in spite of the lack of studies with the endpoint recurrence-free, or, respectively, total survival. However, it should only be used in cases with relevant impairments of quality of life due to vaginal atrophy and after appropriate informed consent discussions with the individual patient.

\section{Androgens for Vaginal Atrophy \\ $\nabla$}

Beside the described estrogen receptors, vulva and vagina also possess androgen receptors. On the basis of recent data it can be assumed that estrogen receptors are important in the regulation of the number of androgen receptors in vaginal epithelium. The receptor density correlates well with the VMI and is lower in cases of vaginal atrophy [44].

However, only very few data are available on vaginal testosterone treatment after breast cancer. In a small phase I/II trial, 21 postmenopausal breast cancer patients under AI therapy with symptomatic vaginal atrophy were treated with a topical testosterone ointment in various doses for 28 days. A significant improvement of the atrophy complaints in the absence of elevated estradiol or estrone serum levels was observed [45]. Further results of prospective randomised trials on larger patient numbers are still lacking.

\section{Alternative Non-Hormonal Treatment Options}

$\nabla$

Alternative treatment forms such as glide agents, lubricants, humectants or also topical anaesthetics are also available. Bygdeman and Swahn demonstrated significant improvements in vaginal dryness, pruritus and dyspareunia through the use of a nonhormonal vaginal ointment [46]. However, any improvement of symptoms achieved by these alternative methods is generally only of short duration. These treatment options can only be recommended for the short-term relief of symptoms but are not suitable to eliminate vaginal atrophy.

\section{Conclusions \\ $\nabla$}

Topical HT is the means of choice for the treatment of clinically symptomatic vaginal atrophy. An elevation of the serum estrogen levels cannot be excluded with certainty on the basis of the currently available data. Thus, an unambiguous assessment of topical HT after breast cancer has been diagnosed cannot be made at present. As a result, the use of topical HT after the diagnosis of breast cancer has been made should only be initiated in cases where the patient experiences a high degree of distress with corresponding impairments in quality of life and after comprehensive consultations with the patient about the current state of knowledge and the fact that the possibility of an increased risk of recurrence cannot be excluded. When a topical hormone-containing therapy is used, an ultralow dosed formulation (e.g., estriol $0.03 \mathrm{mg}$ ) should be used whenever possible in the first few weeks. Further prospective randomised trials are needed to assess the safety of topical HT for breast cancer patients, especially in the light of the degree of distress and impairments in quality of life experienced by these patients.

\section{Conflict of Interest}

O. Ortmann, S. Buchholz, S. Seitz and M. Moegele have received support for research from Medinova AG.

\section{References}

1 Levi F, Bosetti C, Lucchini F et al. Monitoring the decrease in breast cancer mortality in Europe. Eur J Cancer Prev 2005; 14: 497-502

2 Couzi RJ, Helzlsouer KJ, Fetting JH. Prevalence of menopausal symptoms among women with a history of breast cancer and attitudes toward estrogen replacement therapy. J Clin Oncol 1995; 13: 2737-2744

3 Ganz PA, Rowland JH, Desmond K et al. Life after breast cancer: understanding women's health-related quality of life and sexual functioning. J Clin Oncol 1998; 16: 501-514

4 Baumgart J, Nilsson K, Stavreus-Evers A et al. Urogenital disorders in women with adjuvant endocrine therapy after early breast cancer. Am J Obstet Gynecol 2011; 204: 26.e1-26.e7

5 Chin SN, Trinkaus M, Simmons C et al. Prevalence and severity of urogenital symptoms in postmenopausal women receiving endocrine therapy for breast cancer. Clin Breast Cancer 2009; 9: 108-117

6 Jones SE, Cantrell J, Vukelja S et al. Comparison of menopausal symptoms during the first year of adjuvant therapy with either exemestane or tamoxifen in early breast cancer: report of a Tamoxifen Exemestane Adjuvant Multicenter trial substudy. J Clin Oncol 2007; 25: 4765-4771

7 Eisemann N, Waldmann A, Katalinic A. Epidemiology of breast cancercurrent figures and trends. Geburtsh Frauenheilk 2013; 73: 130-135

8 Cella D, Fallowfield LJ. Recognition and management of treatment-related side effects for breast cancer patients receiving adjuvant endocrine therapy. Breast Cancer Res Treat 2008; 107: 167-180 
9 North American Menopause Society. The role of local vaginal estrogen for treatment of vaginal atrophy in postmenopausal women: 2007 position statement of the North American Menopause Society. Menopause 2007; 14: 355-369

10 Ortmann O, Dören M, Windler E. Hormone therapy in perimenopause and postmenopause (HT): interdisciplinary S3 guideline, Association of the Scientific Medical Societies in Germany AWMF 015/062-short version. Arch Gynecol Obstet 2011; 284: 343-355

11 Fick E-M, Anzeneder T, Katalinic A et al. Bisphosphonates and their role in therapy for breast cancer - results from the PATH Biobank. Geburtsh Frauenheilk 2013; 73: 412-421

12 Rossouw JE, Anderson GL, Prentice RL et al. Risks and benefits of estrogen plus progestin in healthy postmenopausal women: principal results from the Women's Health Initiative randomized controlled trial. JAMA 2002; 288: 321-333

13 Chlebowski R, Anderson G, Gass M. Estrogen plus progestin and breast cancer incidence and mortality in postmenopausal women. JAMA 2010; 304: 1684-1692

14 Prentice R, Manson J, Langer R et al. Benefits and risks of postmenopausal hormone therapy when it is initiated soon after menopause. Am J Epidemiol 2009; 170: 12-23

15 LaCroix AZ, Chlebowski RT, Manson JE et al. Health outcomes after stopping conjugated equine estrogens among postmenopausal women with prior hysterectomy: a randomized controlled trial. JAMA 2011; 305: 1305-1314

16 Shah NR, Borenstein J, Dubois RW. Postmenopausal hormone therapy and breast cancer: a systematic review and meta-analysis. Menopause 2005; 12: 668-678

17 Greiser CM, Greiser EM, Doren M. Menopausal hormone therapy and risk of breast cancer: a meta-analysis of epidemiological studies and randomized controlled trials. Hum Reprod Update 2005; 11: 561-573

18 Lee SA, Ross RK, Pike MC. An overview of menopausal oestrogen-progestin hormone therapy and breast cancer risk. Br J Cancer 2005; 92: 2049-2058

19 Collins JA, Blake JM, Crosignani PG. Breast cancer risk with postmenopausal hormonal treatment. Hum Reprod Update 2005; 11: 545-560

$20 \mathrm{Col} N F$, Hirota $L K$, Orr RK et al. Hormone replacement therapy after breast cancer: a systematic review and quantitative assessment of risk. J Clin Oncol 2001; 19: 2357-2363

21 Holmberg $L$, Anderson H. HABITS (hormonal replacement therapy after breast cancer - is it safe?), a randomised comparison: trial stopped. Lancet 2004; 363: 453-455

22 von Schoultz E, Rutqvist LE; Stockholm Breast Cancer Study Group. Menopausal hormone therapy after breast cancer: the Stockholm randomized trial. J Natl Cancer Inst 2005; 97: 533-535

23 Kenemans P, Bundred NJ, Foidart JM. Safety and efficacy of tibolone in breast-cancer patients with vasomotor symptoms: a double-blind, randomised, non-inferiority trial. Lancet Oncol 2009; 10: 135-146

24 Cardozo L, Bachmann G, McClish D et al. Meta-analysis of estrogen therapy in the management of urogenital atrophy in postmenopausal women: second report of the Hormones and Urogenital Therapy Committee. Obstet Gynecol 1998; 92: 722-727

25 Suckling J, Lethaby A, Kennedy R. Local oestrogen for vaginal atrophy in postmenopausal women. Cochrane Database Syst Rev 2003; 4: CD001500

26 North American Menopause Society. Estrogen and progestogen use in postmenopausal women: 2010 position statement of The North American Menopause Society. Menopause 2010; 17: 242-255

27 Mettler L, Olsen PG. Long-term treatment of atrophic vaginitis with low-dose oestradiol vaginal tablets. Maturitas 1991; 14: 23-31

28 Weisberg E, Ayton R, Darling G. Endometrial and vaginal effects of lowdose estradiol delivered by vaginal ring or vaginal tablet. Climacteric 2005; 8: 83-92
29 Gerbaldo D, Ferraiolo A, Croce $S$ et al. Endometrial morphology after 12 months of vaginal oestriol therapy in postmenopausal women. Maturitas 1991; 13: 269-274

30 Luisi M, Franchi F, Kicovic PM. A group-comparative study of effects of Ovestin ${ }^{\circledR}$ cream versus Premarin cream in postmenopausal women with vaginal atrophy. Maturitas 1980; 2: 311-319

31 Buhling KJ, Eydeler U, Borregaard S et al. Systemic bioavailability of estriol following single and repeated vaginal administration of $0.03 \mathrm{mg}$ estriol containing pessaries. Arzneimittelforschung 2012; 62: 378-383

32 Mazur D, Vens-Cappell B, Lohmann K et al. Fractionated use of a $17 \beta$ estradiol cream for the treatment of vaginal atrophy in postmenopausal women. Geburtsh Frauenheilk 2005; 65: 584-589

33 Simon JA, Komi J. Vulvovaginal atrophy negatively impacts sexual function, psychosocial wellbeing, and partner relationships. N Am Menopause Assoc 2007; 10: 3-6

34 Graziottin A. Sexuality in the Menopause. In: Studd J, ed. The Yearbook of Royal College of Obstetrics and Gynecologists. London: RCOG Press; 1997: 201-209

35 Kendall A, Dowsett M, Folkerd E et al. Caution: vaginal estradiol appears to be contraindicated in postmenopausal women on adjuvant aromatase inhibitors. Ann Oncol 2006; 17: 584-587

36 Wills S, Ravipati A, Venuturumilli P et al. Effects of vaginal estrogens on serum estradiol levels in postmenopausal breast cancer survivors and women at risk of breast cancer taking an aromatase inhibitor or a selective estrogen receptor modulator. J Oncol Pract 2012; 8: 144-148

37 Dew JE, Wren BG, Eden JA. A cohort study of topical vaginal estrogen therapy in women previously treated for breast cancer. Climacteric 2003; 6: 45-52

38 Trevoux $R$, van der Velden $W H$, Popović $D$. Ovestin vaginal cream and suppositories for the treatment of menopausal vaginal atrophy. Reproduccion 1982; 6: 101-106

39 Griesser H, Skonietzki S, Fischer T et al. Low dose estriol pessaries for the treatment of vaginal atrophy: a double-blind placebo-controlled trial investigating the efficacy of pessaries containing $0.2 \mathrm{mg}$ and $0.03 \mathrm{mg}$ estriol. Maturitas 2012; 71: 360-368

40 Pfeiler G, Glatz C, Königsberg $R$. Vaginal estriol to overcome side-effects of aromatase inhibitors in breast cancer patients. Climacteric 2011; 14 : 339-344

41 Biglia N, Peano E, Sgandurra P et al. Low-dose vaginal estrogens or vaginal moisturizer in breast cancer survivors with urogenital atrophy: a preliminary study. Gynecol Endocrinol 2010; 26: 404-412

42 Mattsson LA, Cullberg G. Vaginal absorption of two estriol preparations. A comparative study in postmenopausal women. Acta Obstet Gynecol Scand 1983; 62: 393-396

43 Neven P, Donders G, Moegele $M$ et al. Ultra-low dose vaginal estriol and Lactobacillus acidophilus (Gynoflor ${ }^{\circledR}$ ) in early breast cancer survivors on aromatase inhibitors: pharmacokinetic, efficacy and safety results from a phase I study. San Antonio Breast Cancer Symposium 2012 Poster Presentation

44 Taylor AH, Guzail M, Al-Azzawi F. Differential expression of oestrogen receptor isoforms and androgen receptor in the normal vulva and vagina compared with vulval lichen sclerosus and chronic vaginitis. $\mathrm{Br}$ J Dermatol 2008; 158: 319-328

45 Witherby S, Johnson J, Demers L et al. Topical testosterone for breast cancer patients with vaginal atrophy related to aromatase inhibitors: a phase I/II study. Oncologist 2011; 16: 424-431

46 Bygdeman M, Swahn ML. Replens versus dienoestrol cream in the symptomatic treatment of vaginal atrophy in postmenopausal women. Maturitas 1996; 23: 259-263

47 Sturdee DW, Panay N. Recommendations for the management of postmenopausal vaginal atrophy. Climacteric 2010; 13: 509-522 